\title{
POLITISASI LINGKUNGAN OLEH AKTOR PERHUTANI DALAM KASUS KOPERASI TAMBANG INDONESIA III (TIGA) DI KABUPATEN MALANG-JAWA TIMUR
}

\author{
Genta Mahardhika Rozalinna dan Lutfi Amiruddin \\ Departemen Sosiologi, Universitas Brawijaya \\ Email: gmrozalinna@ub.ac.id
}

\begin{abstract}
The existence of mining industry namely Koperasi Tambang III (KTI III) in Golo beach, Wojo Village, Gedangan, Malang District, brought negative impact socially and ecologically. Unfortunately, State Forestry Company (Perusahaan Umum Kehutanan Negara/Perum Perhutani) was involved to share their land as location of iron sand mining activity. Perhutani, as a State-Owned Enterprises (Badan Usaha Milik Negara/BUMN), has a contradicting roles at the same time, to manage natural resource of the forest and accumulate profit. The aim of this article is to depict the process of politization of environment done by Perhutani, based on dimensions (daily, episodic, and systemic), scales (local and regional), and power networks (local and regional). Through qualitative method with single instrumental case study approach, we find out that Perhutani has been the subject and object of politization by the bigger economic-political power. On three dimensions (daily, episodic, and systemic), we stated there are two configurations of Perhutani's roles; first, politizing Golo beach through transform Resort Polisi Hutan (RPH). Second, Golo beach has politized by Malang Government as well as KTI III through transforming the Space Planing (Rencana Tata Ruang Wilayah/RTRW). On the local and regional scale, Perhutani seen by the local community and government, has brought not only the job opportunity, but on contrary the ecological damage. On the local power network, Perhutani was the subject to politize local community and government. However, on the divergent side, it was the object of politization done by KTI III and Malang Government.
\end{abstract}

Keywords: Iron Sand Perhutani; Koperasi Tambang Indonesia III; Mining Industry; Politization of Environment.

\footnotetext{
ABSTRAK

Kehadiran industri pertambangan Koperasi Tambang Indonesia III (KTI III) di wilayah pesisir Pantai Golo, Desa Wojo, Kecamatan Gedangan, Kabupaten Malang, Jawa Timur membawa dampak negatif dalam aspek sosial dan ekologis. Akan tetapi, KTI III melibatkan Perhutani yang lahannya ditempati sebagai wilayah penambangan pasir besi. Perhutani merupakan aktor dari negara yang memiliki peran yang bertentangan; mengelola sumber daya hutan, tetapi sebagai BUMN bertugas mencari keuntungan. Tujuan penelitian ini adalah untuk menggambarkan proses politisasi lingkungan oleh Perhutani berdasarkan dimensi (harian, episodik, dan sistemik), skala (lokal dan regional), dan jejaring relasi kekuasaan (lokal dan regional). Melalui metode kualitatif dengan pendekatan studi kasus instrumental tunggal, maka ditemukan hasil bahwa Perhutani menjadi subjek politisasi sekaligus menjadi objek politisasi lingkungan oleh kepentingan ekonomi politik yang lebih besar. Pada ketiga dimensi (harian, episodik, dan sistemik) ditemukan dua konfigurasi dari peran Perhutani, yaitu pertama, mempolitisasi kawasan Pantai Golo dengan mengubah Resort Polisi Hutan (RPH). Kedua, area Pantai Golo dipolitisasi oleh pemerintah dan KTI III melalui perubahan Rencana Tata Ruang Wilayah/RTRW Kabupaten Malang. Dalam skala lokal dan regional, Perhutani dipandang masyarakat dan pemerintah daerah telah
} 
memberi manfaat berupa terbukanya lapangan pekerjaan, tetapi juga membawa dampak kerusakan ekologis. Secara jejaring relasi kekuasaan lokal, Perhutani menjadi subjek dalam mempolitisasi masyarakat dan pemerintah Desa Wojo, tetapi dalam relasi kekuasaan regional Perhutani justru menjadi objek politasi oleh KTI III dan pemerintah Kabupaten Malang.

Kata Kunci: Industri Tambang; Koperasi Tambang Indonesia III; Pasir Besi; Perhutani; Politik Lingkungan.

\section{PENGANTAR}

Penataan ruang suatu wilayah merupakan pertarungan kepentingan dari berbagai macam aktor. Terlebih jika ruang tersebut menyimpan sumber daya bernilai ekonomi tinggi maka para aktor berupaya mendapatkan kekuaaan lebih atas penguasaan sumber daya di dalamnya. Noor dan Ni'am menyatakan adu kekuatan antara korporasi dan pemangku jabatan dengan masyarakat adat lokal terlihat nyata. Hal ini tidak dapat dipungkiri juga terjadi pada kegiatan penambangan pasir besi di Pantai Golo, Desa Wojo, Kecamatan Gedangan, Kabupaten Malang, Jawa Timur (Noor dan Ni'am, (2011:5).

Perebutan ruang dalam penelitian ini berhubungan dengan pertarungan dalam penguasaan sumber daya tambang oleh korporasi dengan masyarakat setempat yang terancam ruang sosial dan ekologisnya. Akan tetapi, peran negara justru seolah-olah memberikan keleluasaan bagi pertarungan ruang. Pemerintah Provinsi Jawa Timur telah menetapkan Peraturan Daerah Nomor 6 Tahun 2006 tentang Rencana Tata Ruang Wilayah/ RT-RW Jawa Timur Tahun 2006-2020 terkait zonasi potensi tambang di wilayah selatan Jawa Timur. Potensi di wilayah selatan Jawa Timur terdiri dari bahan tambang seperti alumino sikat, mineral lempung, kelompok mineral karbonat, kelompok mineral agregat serta kelompok pasir kuarsa, fosfat, gypsum, dan mineral lain (Tim Riset Java Collapse, 2010:185). Melalui peraturan daerah di Provinsi Jawa Timur, Pemerintah Kabupaten Malang menurunkannya pada Peraturan Daerah Nomor 3 Tahun 2010 tentang Rencana Tata
Ruang Wilayah/ RT-RW Kabupaten Malang yakni pada Pasal 46 disebutkan adanya potensi pertambangan pasir besi di wilayah Kecamatan Gedangan. Peraturan daerah ini mampu mengantarkan Koperasi Tambang Indonesia III yang selanjutnya akan disebut dengan KTI III beroperasi di wilayah Pantai Golo semenjak tahun 2013. Akan tetapi, di saat yang sama menurut Nurhadi dan Rozalinna (2015:7), peraturan daerah tersebut juga mengatur bahwa Kecamatan Gedangan pada Pasal 49 masuk ke dalam kawasan permukiman pedesaan pesisir pantai, Pasal 54 masuk ke dalam wilayah konservasi hutan dan pantai, dan juga pada Pasal 40 huruf 5 masuk dalam wilayah rawan gempa. Perangkat aturan tersebut membuat pertentangan kepentingan antara eksploitasi sumber daya tambang dengan tempat tinggal, konservasi, dan daerah rawan bencana semakin terbuka.

Wilayah penambangan pasir besi di Pantai Golo masuk di dalam penguasaan Perhutani. Peran penguasaan Perhutani dapat dilihat melalui Peraturan Daerah Nomor 3 Tahun 2010 tentang Rencana Tata Ruang Wilayah/ RT-RW Kabupaten Malang, pada Pasal 41 dijelaskan bahwa terdapat kawasan pantai berhutan bakau, termasuk pula di Pasal 43 dan 44 tentang hutan rakyat di wilayah Kecamatan Gedangan. Melalui Pasal 43 dan 44, tersirat bahwa pengelolaan hutan dikuasakan kepada rakyat yang tinggal di sekitar tepi hutan. Akan tetapi, faktanya kedatangan KTI III justru diberi penguasaan hutan oleh Perhutani seluas 98.560 meter persegi pada tahun 2012 . Menurut Nurhadi dan Rozalinna (2015:1718), proses pengalihan kuasa dilakukan secara halus pertama-tama melalui proses semacam tanggung jawab sosial perusahaan (Corporate Social Responsibility/CSR) yang mana KTI III melakukan reboisasi di wilayah Perhutani dengan alih-alih dapat dimanfaatkan oleh masyarakat sebagai hutan rakyat. Akan tetapi, pada tahun 2012 secara tiba-tiba muncul izin pertambangan rakyat yang dikeluarkan oleh Pemerintah Kabupaten Malang atas nama KTI III justru pada wilayah yang dikenai kegiatan reboisasi. Berdirinya perusahaan tambang pada akhirnya justru menciptakan bencana karena 
relasi-relasi dari para aktor yang diasumsikan memiliki perbedaan kepentingan. Seperti yang dinyatakan oleh McMichael (2009) bahwa bencana semburan lumpur Lapindo akibat aktivitas pengeboran di tengah pemukiman padat penduduk nyatanya telah menyebabkan banyak orang kehilangan tempat hidup yang layak.

Adanya pemberian kekuasaan kepada KTI III menunjukkan kekuasaan politisasi dari Perhutani. Melalui Peraturan Pemerintah Nomor 72 Tahun 2010 tentang Perusahaan Umum Perum Kehutanan Negara (Perum Perhutani) Pasal 1 bahwa tata hutan dan penyusunan rencana pengelolaan hutan, pemanfaatan hutan, rehabilitasi, dan reklamasi hutan, serta perlindungan hutan dan konservasi alam berada di dalam kekuasaan Perhutani. Meskipun dianggap sebagai bagian dari aktor negara, tetapi Perhutani juga memiliki tugas mencari keuntungan dikarenakan termasuk dalam salah satu Badan Usaha Milik Negara (BUMN).

Penelitian ini menggunakan metode kualitatif dengan pendekatan studi kasus instrumental tunggal. Menurut Denzin dan Lincoln (2009), intepretasi data dilakukan dalam tiga langkah yakni membuat teks lapangan (field text) meliputi catatan dan dokumen lapangan; menciptakan ulang teks lapangan dalam bentuk dokumen interpretasi; dan menghasilkan teks umum (public text) yang akan hadir di hadapan pembaca. Selain itu, penamaan lokasi penelitian mulai dari pantai, desa, bahkan informan disamarkan untuk melindungi kerahasiaan dan keamanan para informan sebagai etika penelitian.

Pendekatan studi kasus tipe instrumental tunggal (Yin, 2013) digunakan sebagai upaya memahami fokus masalah melalui logika penjodohan pola tipe kedua yaitu eksplanasi tandingan dengan telah menentukan variabel independen. Walaupun desain kasus tunggal yakni politisasi lingkungan oleh Perhutani, tetapi ternyata muncul aktor politisasi lingkungan lainnya yang sama-sama menguasai ruang ekologis masyarakat di Desa Wojo.

Dalam pelaksanaan pencarian data, penulis menghadapi kendala berupa ketertutupan informasi dari pihak Perhutani. Pada beberapa kesempatan wawancara, pihak Perhutani menolak membicarakan masalah KTI III di wilayah Perhutani. Perhutani Kabupaten Malang yang menjadi informan dalam tulisan ini beralasan bahwa masalah perizinan tambang bukan menjadi wewenang mereka. Ada keengganan untuk membicarakan perihal masalah ini kepada penulis. Dengan kondisi demikian, beberapa langkah alternatif dilakukan. Penjabaran langkah-langkah menjalankan metode penelitian di dalam penelitian ini disajikan pada tabel 1 .

Tabel 1

Metode Penelitian

\begin{tabular}{|c|c|c|c|}
\hline Langkah-langkah & Tahapan Kerja & Target Capaian Kegiatan & $\begin{array}{l}\text { Kendala dalam Menjalankan } \\
\text { Target Capaian Kegiatan }\end{array}$ \\
\hline \multirow[t]{2}{*}{$\begin{array}{l}\text { Proses pembuatan } \\
\text { teks lapangan } \\
\text { (field text) } \\
\text { meliputi catatan } \\
\text { dan dokumen } \\
\text { lapangan }\end{array}$} & $\begin{array}{l}\text { Tahap 1: } \\
\text { Mengumpulkan dan } \\
\text { mengidentifikasi semua } \\
\text { aturan tata kelola ruang } \\
\text { yang diperuntukkan bagi } \\
\text { wilayah pertambangan di } \\
\text { Kabupaten Malang }\end{array}$ & $\begin{array}{l}\text { 1. Pengajuan perizinan } \\
\text { 2. Penentuan target } \\
\text { informan utama } \\
\text { 3. Penentuan target utama } \\
\text { informan pendukung } \\
\text { 4. Pencarian data primer } \\
\text { 5. Pencarian data sekunder } \\
\text { 6. Laporan analisa data }\end{array}$ & $\begin{array}{l}\text { kendala pada tahap kedua } \\
\text { yaitu Perhutani sebagai } \\
\text { aktor utama menolak untuk } \\
\text { dilakukannya perizinan } \\
\text { penelitian. }\end{array}$ \\
\hline & $\begin{array}{l}\text { Tahap 2: } \\
\text { Menetapkan Perhutani } \\
\text { sebagai variabel } \\
\text { independen dalam kasus } \\
\text { politisasi lingkungan }\end{array}$ & $\begin{array}{l}\text { 1. Penentuan target utama } \\
\text { informan pendukung } \\
\text { 2. Pencarian data sekunder } \\
\text { 3. Laporan analisa data }\end{array}$ & $\begin{array}{l}\text { Penentuan target informan } \\
\text { utama (dari pihak Perhutani) } \\
\text { gagal karena penolakan dari } \\
\text { Perhutani sendiri. }\end{array}$ \\
\hline
\end{tabular}


Lanjutan Tabel 1.

\begin{tabular}{|c|c|c|c|}
\hline Langkah-langkah & Tahapan Kerja & Target Capaian Kegiatan & $\begin{array}{l}\text { Kendala dalam Menjalankan } \\
\text { Target Capaian Kegiatan }\end{array}$ \\
\hline & $\begin{array}{l}\text { Tahap 3: } \\
\text { Menelusuri kembali hasil } \\
\text { penelitian internal yang } \\
\text { pernah dilakukan pada } \\
\text { tahun } 2015 \text { terkait relasi } \\
\text { yang terbangun antara } \\
\text { masyarakat lingkar } \\
\text { dalam tambang dengan } \\
\text { Perhutani yang bersifat } \\
\text { instrumental tunggal }\end{array}$ & $\begin{array}{l}\text { 1. Pengajuan perizinan } \\
\text { 2. Penentuan target } \\
\text { informan utama } \\
\text { 3. Penentuan target utama } \\
\text { informan pendukung } \\
\text { 4. Pencarian data primer } \\
\text { 5. Pencarian data sekunder } \\
\text { 6. Laporan analisa data }\end{array}$ & $\begin{array}{l}\text { Sebagai solusi atas kegagalan } \\
\text { penentuan informan utama, } \\
\text { penentuan informan } \\
\text { pendukung menjadi prioritas } \\
\text { dalam tahap 2. Informan } \\
\text { pendukung di sini adalah aktor- } \\
\text { aktor yang terlibat dalam kasus } \\
\text { KTI III di Desa Wojo meliputi } \\
\text { pemerintah desa, pemerintah } \\
\text { kabupaten, dan NGO. }\end{array}$ \\
\hline & $\begin{array}{l}\text { Tahap 4: } \\
\text { Menelusuri kembali hasil } \\
\text { penelitian internal yang } \\
\text { pernah dilakukan pada } \\
\text { tahun } 2016 \text { terkait relasi } \\
\text { yang terbangun antara } \\
\text { masyarakat lingkar } \\
\text { luar tambang dengan } \\
\text { Perhutani yang bersifat } \\
\text { instrumental tunggal }\end{array}$ & $\begin{array}{l}\text { 1. Pengajuan perizinan } \\
\text { 2. Penentuan target } \\
\text { informan utama } \\
\text { 3. Penentuan target utama } \\
\text { informan pendukung } \\
\text { 4. Pencarian data primer } \\
\text { 5. Pencarian data sekunder } \\
\text { 6. Laporan analisa data }\end{array}$ & $\begin{array}{l}\text { Tertutupnya informasi } \\
\text { apapun dari pihak Perhutani } \\
\text { menyebabkan penulis sama } \\
\text { sekali tidak mendapatkan data } \\
\text { primer dari pihak Perhutani. }\end{array}$ \\
\hline \multirow[t]{2}{*}{$\begin{array}{l}\text { Menciptakan } \\
\text { ulang teks } \\
\text { lapangan }\end{array}$} & $\begin{array}{l}\text { Tahap 5: } \\
\text { Melakukan wawancara } \\
\text { mendalam dengan } \\
\text { Perhutani }\end{array}$ & - & $\begin{array}{l}\text { Pencarian data sekunder lebih } \\
\text { mudah dilakukan dari pada data } \\
\text { primer. Sehingga semua tahap } \\
\text { dapat terpenuhi dengan baik. }\end{array}$ \\
\hline & $\begin{array}{l}\text { Tahap 6: } \\
\text { Membuat dan meng- } \\
\text { interpretasi kategorisasi } \\
\text { tema yang menunjukkan } \\
\text { Perhutani sebagai } \\
\text { variabel independen }\end{array}$ & - & - \\
\hline $\begin{array}{l}\text { Proses } \\
\text { penghasilan teks } \\
\text { umum }\end{array}$ & $\begin{array}{l}\text { Tahap 7: } \\
\text { Menghasilkan laporan } \\
\text { studi kasus politisasi } \\
\text { lingkungan dilakukan } \\
\text { oleh Perhutani sebagai } \\
\text { aktor negara }\end{array}$ & - & - \\
\hline
\end{tabular}

\section{PEMBAHASAN}

\section{Perhutani dalam Dimensi Tambang Pasir Besi Pantai Golo}

Kegiatan pariwisata merupakan salah satu potensi yang menjanjikan terutama bagi Kabupaten Malang, Jawa Timur. Sederatan pantai-pantai di sepanjang pesisir selatan dikembangkan oleh Pemerintah Kabupaten Malang secara besar-besaran. Kondisi ini didukung juga dengan adanya pembangunan infrastruktur Jalur Lingkar Selatan (JLS) yang turut mendukung gencarnya promosi pariwisata. Banyaknya pantai yang telah berkembang di sepanjang pesisir pantai selatan Kabupaten Malang misalnya seperti Pantai Kondang Merak, Balekambang, Nganteb, Batu Bengkung, Goa Cina, Sendang Biru, juga terdapat satu pantai yang keberadaannya menjadi lokasi dalam penelitian ini yaitu Pantai Golo. Pantai Golo merupakan pantai yang mengalami perubahan status Resort Polisi Hutan (RPH) sebelum beroperasinya KTI III. Keberhasilan KTI III masuk ke kawasan Pantai Golo untuk menambang pasir besi tidaklah sendirian, muncul beberapa aktor lain yang berada di belakangnya, salah satunya pihak Perhutani. Di lain sisi, kemunculan aktor-aktor lain yang tidak bersepakat juga hadir dalam menolak KTI III.

Kerangka konseptual tentang politik lingkungan yang dikemukakan oleh Bryant dan Bailey (2005), mengasumsikan bahwa politisasi lingkungan berupa sumber daya alam yang dilakukan tidak hadir oleh seorang aktor, tetapi 
akan ada aktor-aktor lain yang juga berjejaring dalam membangun relasi kekuasaan. Terdapat proses-proses pertentangan dan pergulatan di antara para aktor dalam memenuhi kepentingannya. Aktor-aktor yang muncul secara konseptual dalam membangun relasi kekuasaan pada politisasi lingkungan terdiri dari lima aktor yaitu antara lain negara, lembaga multilateral, korporasi transnasional (bisnis), Environment Non-Government Organization (ENGO), dan masyarakat (Bryant dan Bailey, 2005). Dalam penelitian ini ditemukan bahwa aktor Perhutani muncul dengan dua konfigurasi yaitu sebagai aktor negara dan bisnis dalam kegiatan tambang di Pasir Golo. Dalam penelitian ini aktor Perhutani menjadi pihak utama yang diteliti karena ada kendala perizinan, maka Perhutani menolak untuk berbicara terkait eksplorasi pasir besi di Pantai Golo. Untuk itu, upaya untuk melihat politisasi lingkungan yang terjadi, maka proses pencarian data dilanjutkan dengan melakukan wawancara terhadap aktor-aktor lain yang juga muncul, mulai dari masyarakat lokal, pemerintah Kabupaten Malang serta tentunya
KTI III. Dengan demikian, politisasi lingkungan yang terjalin dalam kegiatan penambangan ini dapat membantu dalam menjelaskan peran dari Pihak Perhutani.

Kehadiran Perhutani yang memiliki dua konfigurasi menjadi penting untuk diteliti, karena secara konseptual menjadi kritik bagi konseptual politisasi lingkungan yang dikemukakan oleh Bryant dan Bailey (2005), Perhutani muncul dengan dua konfigurasi yaitu sebagai aktor negara dan bisnis. Dua konfigurasi dari Perhutani akan mempengaruhi proses politisasi lingkungan yang terjadi. Sebagai pemangku wilayah hutan, maka Perhutani bertanggung jawab atas masuknya kegiatan penambangan pasir besi oleh KTI III. Dalam keberlanjutannya, tidak dapat dipungkiri bahwa peran Perhutani membawa dampak atas politisasi lingkungan di Pantai Golo. Dampak tersebut tergambarkan dalam dimensi politisasi lingkungan mulai dari harian, episodik, dan sistemik yang disajikan pada tabel 2.

Tabel 2

Dimensi Politisasi Lingkungan oleh Aktor Perhutani

\begin{tabular}{|c|c|c|c|c|c|}
\hline Dimensi & $\begin{array}{c}\text { Perubahan } \\
\text { Fisik }\end{array}$ & Dampak & $\begin{array}{c}\text { Dampak } \\
\text { Keberlanjutan } \\
\text { Terhadap Manusia } \\
\end{array}$ & Respons Politik & Konsep Kunci \\
\hline \multirow[t]{2}{*}{ Harian } & $\begin{array}{l}\text { Masuknya } \\
\text { kepentingan } \\
\text { KTI III dalam } \\
\text { mengelola pasir } \\
\text { besi di Pantai } \\
\text { Golo yang } \\
\text { merupakan } \\
\text { wilayah } \\
\text { Perhutani RPH } \\
\text { Bantur. }\end{array}$ & $\begin{array}{l}\text { Perubahan } \\
\text { wilayah RPH } \\
\text { Pantai Golo } \\
\text { dari Bantur ke } \\
\text { Sumbermanjing } \\
\text { Kulon. }\end{array}$ & $\begin{array}{l}\text { Perubahan wilayah } \\
\text { RPH Pantai Golo } \\
\text { menyebabkan RPH } \\
\text { Bantur tidak lagi } \\
\text { memiliki kewenangan } \\
\text { atas Pantai Golo. } \\
\text { Konsekuensinya } \\
\text { adalah Perhutani } \\
\text { terpojokkan dan } \\
\text { termarjinalkan di } \\
\text { wilayahnya sendiri } \\
\text { demi kepentingan } \\
\text { KTI III. }\end{array}$ & $\begin{array}{l}\text { Perhutani } \\
\text { mengalami } \\
\text { kebingungan } \\
\text { atas bergesernya } \\
\text { patok-patok } \\
\text { wilayah sebelum } \\
\text { masuknya KTI III } \\
\text { (perubahan RPH). }\end{array}$ & \multirow[t]{2}{*}{$\begin{array}{l}\text { Perhutani } \\
\text { mempolitisasi } \\
\text { lingkungan } \\
\text { dengan adanya } \\
\text { perubahan RPH. } \\
\text { Sebagai } \\
\text { konsekuensinya } \\
\text { adalah } \\
\text { masyarakat } \\
\text { menjadi } \\
\text { termarjinalkan. }\end{array}$} \\
\hline & $\begin{array}{l}\text { Terjadi pem- } \\
\text { babatan } \\
\text { tanaman } \\
\text { pandan pantai } \\
\text { dan pem- } \\
\text { bakaran lahan } \\
\text { pertanian di } \\
\text { sekitar Pantai } \\
\text { Golo. Pantai } \\
\text { Golo }\end{array}$ & $\begin{array}{l}\text { Pantai Golo tidak } \\
\text { lagi produktif } \\
\text { untuk kawasan } \\
\text { pertanian. }\end{array}$ & $\begin{array}{l}\text { Kerusakan pesisir } \\
\text { pantai akibat } \\
\text { pengerukkan dan } \\
\text { penyedotan pasir } \\
\text { besi menyebabkan air } \\
\text { laut masuk hingga } \\
\text { melebihi bibir pantai. }\end{array}$ & $\begin{array}{l}\text { Masyarakat } \\
\text { melakukan } \\
\text { penolakkan } \\
\text { dengan cara } \\
\text { menggerutu dan } \\
\text { marah. }\end{array}$ & \\
\hline
\end{tabular}


Lanjutan Tabel 2.

\begin{tabular}{|c|c|c|c|c|c|}
\hline Dimensi & $\begin{array}{c}\text { Perubahan } \\
\text { Fisik }\end{array}$ & Dampak & $\begin{array}{c}\text { Dampak } \\
\text { Keberlanjutan } \\
\text { Terhadap Manusia }\end{array}$ & Respons Politik & Konsep Kunci \\
\hline & $\begin{array}{l}\text { Rusaknya } \\
\text { jalanan } \\
\text { warga karena } \\
\text { kendaraan } \\
\text { pengangkut } \\
\text { tambang } \\
\text { dengan tonase } \\
\text { tinggi. }\end{array}$ & $\begin{array}{l}\text { Kerusakkan jalan } \\
\text { secara parah } \\
\text { sebagian besar } \\
\text { terjadi di wilayah } \\
\text { Kecamatan } \\
\text { Bantur. }\end{array}$ & $\begin{array}{l}\text { Produktivitas } \\
\text { masyarakat menurun } \\
\text { karena rusaknya } \\
\text { jalan. }\end{array}$ & $\begin{array}{l}\text { Masyarakat me- } \\
\text { lakukan pem- } \\
\text { blokiran jalan } \\
\text { dengan menuntut } \\
\text { adanya perbaikan } \\
\text { jalan. Akan } \\
\text { tetapi, setelah } \\
\text { diperbaiki, } \\
\text { masyarakat } \\
\text { malah menutup } \\
\text { jalan dan } \\
\text { melarang } \\
\text { kendaraan } \\
\text { pengangkut } \\
\text { tambang untuk } \\
\text { melintas. }\end{array}$ & \\
\hline
\end{tabular}

\begin{tabular}{|c|c|c|c|c|c|}
\hline \multirow[t]{3}{*}{ Episodik } & $\begin{array}{l}\text { Perubahan } \\
\text { wilayah RPH } \\
\text { Pantai Golo } \\
\text { dari Bantur ke } \\
\text { Sumbermanjing } \\
\text { Kulon }\end{array}$ & $\begin{array}{l}\text { Muncul } \\
\text { pencaplokkan } \\
\text { wilayah RPH } \\
\text { Bantur. Selain } \\
\text { itu pemindahan } \\
\text { tempat tugas } \\
\text { salah seorang } \\
\text { pegawai } \\
\text { Perhutani yang } \\
\text { justru menolak } \\
\text { adanya tambang. }\end{array}$ & $\begin{array}{l}\text { Munculnya } \\
\text { kekhawatiran apabila } \\
\text { hadir perusahaan } \\
\text { tambang yang jauh } \\
\text { lebih besar secara } \\
\text { investasi, akan dapat } \\
\text { mengubah peraturan. } \\
\text { Pada dasarnya, } \\
\text { wilayah RPH } \\
\text { dievaluasi setiap } 10 \\
\text { tahun sekali, tetapi } \\
\text { dengan munculnya } \\
\text { kepentingan bisnis, } \\
\text { RPH dapat berubah } \\
\text { tidak mengikuti } \\
\text { aturan tersebut. }\end{array}$ & - & \multirow[t]{3}{*}{$\begin{array}{l}\text { Politisasi } \\
\text { lingkungan } \\
\text { yang dilaku- } \\
\text { kan oleh } \\
\text { Perhutani telah } \\
\text { berdampak } \\
\text { pada pemberian } \\
\text { izin oleh } \\
\text { pemerintah desa } \\
\text { pada kegiatan } \\
\text { KTI III. } \\
\text { Kerusakaan } \\
\text { ruang sosial } \\
\text { dan ekologis } \\
\text { akan muncul } \\
\text { bila kegiatan } \\
\text { penambangan } \\
\text { terus } \\
\text { berlangsung. }\end{array}$} \\
\hline & $\begin{array}{l}\text { Aktor } \\
\text { pemerintahan } \\
\text { "terkalahkan" } \\
\text { bila berurusan } \\
\text { dengan pemilik } \\
\text { modal seperti } \\
\text { salah satunya } \\
\text { perusahaan } \\
\text { tambang. }\end{array}$ & $\begin{array}{l}\text { Rusaknya ruang } \\
\text { sosial dan } \\
\text { ekologis saat } \\
\text { berhadapan } \\
\text { dengan struktur } \\
\text { ekonomi yang } \\
\text { lebih kuat. }\end{array}$ & $\begin{array}{l}\text { Investasi dari } \\
\text { pemodal swasta } \\
\text { menjadi ancaman } \\
\text { bagi pemerintahan, } \\
\text { terutama bagi yang } \\
\text { memiliki relasi } \\
\text { kuat dengan kepala } \\
\text { pemerintahan. }\end{array}$ & - & \\
\hline & $\begin{array}{l}\text { Masuknya } \\
\text { kepentingan } \\
\text { KTI III dalam } \\
\text { mengelola pasir } \\
\text { besi di Pantai } \\
\text { Golo. }\end{array}$ & $\begin{array}{l}\text { Bagi beberapa } \\
\text { perangkat desa, } \\
\text { hadirnya KTI III } \\
\text { justru membawa } \\
\text { manfaat positif } \\
\text { karena ekspektasi } \\
\text { untuk bisa } \\
\text { mendapat } \\
\text { manfaat ekonomi. }\end{array}$ & $\begin{array}{l}\text { Terdapat beberapa } \\
\text { pihak desa } \\
\text { yang mengeruk } \\
\text { keuntungan pribadi } \\
\text { atas beroperasinya } \\
\text { KTI III. Di lain sisi, } \\
\text { kerusakkan ekologis } \\
\text { dari Pantai Golo akan } \\
\text { muncul } 5 \text { hingga } 20 \\
\text { tahun ke depan. }\end{array}$ & $\begin{array}{l}\text { Beberapa } \\
\text { perangkat desa } \\
\text { senang dengan } \\
\text { hadirnya KTI III. }\end{array}$ & \\
\hline
\end{tabular}


Lanjutan Tabel 2.

\begin{tabular}{|c|c|c|c|c|c|}
\hline Dimensi & $\begin{array}{l}\text { Perubahan } \\
\text { Fisik }\end{array}$ & Dampak & $\begin{array}{c}\text { Dampak } \\
\text { Keberlanjutan } \\
\text { Terhadap Manusia }\end{array}$ & Respons Politik & Konsep Kunci \\
\hline \multirow[t]{2}{*}{ Sistematik } & $\begin{array}{l}\text { Perubahan } \\
\text { RTRW } \\
\text { Kabupaten } \\
\text { Malang yang } \\
\text { berdampak } \\
\text { pada masuknya } \\
\text { KTI III di } \\
\text { wilayah } \\
\text { Perhutani. }\end{array}$ & $\begin{array}{l}\text { Tahun } 2012 \\
\text { terbit peraturan } \\
\text { daerah tentang } \\
\text { RTRW yang } \\
\text { memperbolehkan } \\
\text { wilayah Pantai } \\
\text { Golo sebagai } \\
\text { lokasi yang } \\
\text { berpotensi } \\
\text { untuk wilayah } \\
\text { pertambangan. } \\
\text { pasir besi di } \\
\text { Pantai Golo } \\
\text { ditolak karena } \\
\text { pantai tersebut } \\
\text { masuk ke dalam } \\
\text { wilayah hutan } \\
\text { lindung. }\end{array}$ & $\begin{array}{l}\text { Perbedaan informasi } \\
\text { terhadap status } \\
\text { Pantai Golo } \\
\text { membawa dampak } \\
\text { pada pemberian } \\
\text { perizinan yang } \\
\text { diterima oleh PT } \\
\text { Marmora (ditolak) } \\
\text { dan KTI III } \\
\text { (diterima). }\end{array}$ & $\begin{array}{l}\text { Pemerintah dan } \\
\text { pihak bisnis } \\
\text { menggunakan } \\
\text { cara-cara mulai } \\
\text { dari mengubah } \\
\text { peraturan sampai } \\
\text { mencari celah } \\
\text { kebijakan yang } \\
\text { telah ada. } \\
\text { Seperti halnya } \\
\text { Pantai Golo yang } \\
\text { berubah status } \\
\text { dari wilayah } \\
\text { hutan lindung } \\
\text { menjadi kawasan } \\
\text { pertambangan. }\end{array}$ & $\begin{array}{l}\text { Pihak Perhutani } \\
\text { berbalik menjadi } \\
\text { terpolitisasi } \\
\text { atas perubahan } \\
\text { wilayah RPH } \\
\text { Pantai Golo } \\
\text { akibat keluarnya } \\
\text { Peraturan } \\
\text { Daerah masalah } \\
\text { RTRW di } \\
\text { Kabupaten } \\
\text { Malang. }\end{array}$ \\
\hline & $\begin{array}{l}\text { Kegiatan } \\
\text { penambangan } \\
\text { oleh KTI III } \\
\text { tidak sesuai } \\
\text { dengan izin } \\
\text { yang diberikan. }\end{array}$ & $\begin{array}{l}\text { Dokumen Upaya } \\
\text { Pengelolaan } \\
\text { Lingkungan } \\
\text { Hidup dan Upaya } \\
\text { Pemantauan } \\
\text { Lingkungan } \\
\text { Hidup (UKL- } \\
\text { UPL) tertulis } \\
\text { bahwa KTI } \\
\text { III berbentuk } \\
\text { koperasi. }\end{array}$ & $\begin{array}{l}\text { Gambaran dari } \\
\text { kegiatan di Pantai } \\
\text { Golo dapat menjadi } \\
\text { pelajaran atas risiko } \\
\text { kerusakan ekologis } \\
\text { yang tidak terduga } \\
\text { oleh masyarakat } \\
\text { sekitar pantai yang } \\
\text { awam terhadap } \\
\text { pembacaan hukum. }\end{array}$ & $\begin{array}{l}\text { Masyarakat } \\
\text { dan Wahana } \\
\text { Lingkungan } \\
\text { Hidup Indonesia } \\
\text { (Walhi) wilayah } \\
\text { Malang melihat } \\
\text { potensi kerusakan } \\
\text { ekologis pada } \\
\text { Pantai Golo. } \\
\text { sedangkanMalang } \\
\text { Corruption Watch } \\
\text { (MCW) melihat } \\
\text { adanya indikasi } \\
\text { kasus korupsi } \\
\text { atas kegiatan KTI } \\
\text { III. }\end{array}$ & \\
\hline
\end{tabular}

Perhutani bertugas sebagaimana dalam PP Nomor 72 Tahun 2010 Pasal 1 tentang tata hutan dan penyusunan rencana pengelolaan hutan, pemanfaatan hutan, rehabilitasi dan reklamasi hutan, serta perlindungan hutan dan konservasi. Dalam hal ini Perhutani yang berada di sekitar wilayah Desa Wojo bertugas juga dalam pengawasan dan pengembangan Pantai Golo dan Ngateb. Berdasarkan temuan di lapangan, kedua pantai ini sebelumnya sama-sama digunakan untuk tujuan wisata. Perubahan terjadi semenjak masuknya KTI III untuk melakukan kegiatan penambangan pasir besi pada tahun 2012 di Pantai Golo. Semenjak itu Pantai Golo menjadi terbatas dan selalu dalam pengawasan pihak KTI III. Seperti yang diungkapkan oleh salah satu perangkat Desa Wojo berikut ini:
"Ya dulu pernah dikelola (untuk wisata), terus ada penambang pasir besi seakan-akan lahan ini dikuasai oleh dia" (Kr, Wawancara, 28 Juli, 2017).

Potensi pasir besi yang sangat potensial di kawasan Pantai Golo menjadi lahan basah untuk menghasilkan pundi-pundi ekonomi yang besar. Akan tetapi, potensi tersebut justru menjadi bumerang di kemudian hari. Selama proses pertambangan pasir besi di kawasan Pantai Golo, terjadi banyak polemik yang mana ada pihak yang merasa mendapat manfaat dan kerugian di wilayah desa mereka sendiri. Dalam dimensi harian, Perhutani mempolitisasi Pantai Golo dengan terlibat pada perubahan RPH. Masuknya KTI III yang memiliki kepentingan untuk mengelola tambang pasir besi yang awalnya merupakan 
wilayah Perhutani RPH Bantur menjadi RPH Sumbermanjing Kulon seperti pernyatan salah seorang informan:

"Awalnya masuk di itu di RPH Bantur. Yo Golo itu. Terus ndak tahu tiba-tiba masuk di RPH Sumbermanjing Kulon" (Rb, Wawancara, 28 Juli, 2017).

Sebagai konsekuensi atas perubahan $\mathrm{RPH}$ tersebut, maka masyarakat menjadi pihak yang turut termarjinalkan. Seperti pernyataan informan berikut selaku masyarakat Desa Wojo:

"Bukan, sudah bukan (dikelola desa), bahkan orang sini mau masuk kesana susah. Yo wajar seh kan masyarakat itu gak boleh masuk wilayah tambang ya kan. Wong ada aturane kayak gitu. Kita ya gak tahu apa yang akan terjadi ndek dalem situ. Itu (aslinya) wilayah buat mincing. Ya memang dari awal masyarakat sini kalau mincing ya daerah situ, di Golo. Sejak ada tambang mau mancing itu susah. Gak dibolehi sama orang tambang". (Rb, Wawancara, 28 Juli, 2017).

Pada dasarnya Perhutani tidak menutup diri dengan hadirnya KTI III, tetapi seharusnya tetaplah menjadi pihak utama. Sementara investor maupun Lembaga Masyarakat Desa Hutan (LMDH) diperlakukan setara karena mereka adalah mitra dari Perhutani. Dasar pengalihan fungsi suatu lahan juga dapat menentukan kebijakan yang dibuat oleh Perhutani, misalnya saja bila lahan tersebut sudah tidak dapat lagi produktif, contohnya saja keberadaan lokasi tambak di Desa Wojo yang berada di wilayah Perhutani. Dalam kasus KTI III justru sebaliknya, Perhutani justru malah masuk dalam dimensi aktor yang tidak hanya melakukan politisasi, tetapi juga terpolitisasi.

Dalam dimensi episodik, politisasi lingkungan yang dilakukan oleh Perhutani melalui perubahan RPH kawasan Pantai Golo telah menyebabkan pihak Pemerintah Desa Wojo juga ikut memberikan izin pada kegiatan di KTI III. Akan tetapi, menurut pengakuan dari salah seorang perangkat, terjadi prokontra di dalam masyarakat dalam menerima kehadiran KTI III. Pihak yang pro terhadap tambang adalah mereka yang merasakan manfaat bantuan-bantuan dari pihak KTI III. Sedangkan yang kontra justru mereka yang berada jauh dari lokasi pertambangan dan tidak pernah dilibatkan, tetapi aksesibilitas jalan umum mereka rusak karena terkena truk pengangkut tambang bertonase tinggi. Berikut kutipan wawancara bersama salah seorang perangkat Desa Wojo:

"Pekerjanya orang sini semua, seneng dulu, jadi pro kontra masalah yang sebagai tenaga kerja. Dan yang katanya orang Jowo itu pengatok nek ngatuk yo seneng tapi nek enek sing gak ngatuk yo geting. Jadi terbelah menjadi dua." (Kr, Wawancara, 28 Juli, 2017).

Dalam dimensi episodik, Perhutani justru balik terpolitisasi atas perubahan dari wilayah RPH Pantai Golo sendiri karena keluarnya Peraturan Daerah masalah RT-RW di Kabupaten Malang. Alasan kuat peneliti memandang Perhutani juga sebagai pihak yang terpolitisasi karena pernyataan tersirat dari salah satu pihak Malang Corruption Watch (MCW):

\begin{abstract}
"Itukan sebenarnya wilayah lindung di pesisir pantai dan di sana juga ada hutan lindungnya dan di area tersebut tidak boleh di tambang. Peraturan Daerah atas RTRW Kabupaten Malang sebelumnya ada, itu sebelumnya ada izin untuk KTI III, tapi sebelumnya juga ada perusahaan yang sudah mengajukan tapi ditolak dengan alasan itu tadi, hutan lindung tidak boleh diberikan IPR. Terus kemudian tahun 2012 bulan Juli itu terbit izin untuk KTI III itu ada selisihnya sebelum terbit izin di bulan Juli itu, di tahun 2012 juga ada pembaharuan perda RTRW yang dulunya tidak boleh ditambang jadi boleh ditambang. Yang dibuat oleh Bappeda. (MCW, Wawancara, 4 Agustus, 2017)
\end{abstract}

Cepatnya proses perubahan RT-RW Kabupaten Malang terkait Pantai Golo merupakan kawasan lindung dan segala bentuk kegiatan eksplorasi pertambangan di kawasan lindung wajib menggunakan AMDAL. Akan tetapi, yang terjadi justru alih fungsi hutan lindung menjadi hutan produksi terbatas. Hal ini dikarenakan lobi-lobi politik yang sangat santer juga terjadi begitu masif mulai dari Bupati, Perhutani, BLH, dan Bapeda terlibat 
di dalamnya karena salah satu anak dari bupati yang mengajukan izin pertambangan tersebut. Perubahan RT-RW ini juga diikuti oleh proses perizinan yang manipulatif dengan menggunakan IPR, tetapi realitanya menggunakan alat berat. Selain itu dokumen perizinan juga menggunakan UKL UPL bukan AMDAL. Proses perizinan yang tidak sesuai diindikasikan memiliki potensi untuk negara mengalami kerugian. Dalam kasus pertambangan pasir besi di Pantai Golo, KTI III menggunakan IPR bukan menggunakan izin usaha pertambangan. Hal ini dilakukan untuk menekan pajak dan biaya produksi.

Langkah yang kemudian dilakukan MCW dan WALHI adalah mencari dokumendokumen terkait perizinan yang dilakukan oleh pihak KTI III. MCW menilai bahwa IPR yang diajukan sangat manipulatif apalagi dokumen yang diajukan hanyalah UKL UPL bukan AMDAL. Sisi koruptif lain yang menjadi sorotan MCW dimulai saat tahun 2012 ketika dikeluarkannya Perda RT-RW yang baru yang memperbolehkan wilayah Pantai Golo menjadi wilayah penambangan. Padahal beberapa waktu sebelumnya ada sebuah perusahaan bernama PT Marmora yang mengajukan IPR untuk penambangan pasir besi di Golo, tetapi tidak diberikan izin karena Peraturan Daerah terkait RTRW Kabupaten Malang menyatakan bahwa kawasan tersebut merupakan kawasan hutan lindung sehingga tidak boleh ditambang. Hingga saat ini sebenarnya MCW masih menunggu hasil dari KPK terkait kelangsungan dari kasus penambangan pasir besi di Pantai Golo.

\section{Silang Sengkarut Skala Aktor di Tanah Perhutani}

Kawasan hutan-pantai berdasarkan RTRW Kabupaten Malang merupakan kawasan konservasi yang kemudian secara tiba-tiba berubah menjadi kawasan yang boleh ditambang dan hal tersebut menyebabkan beberapa permasalahan. Pantai wisata yang tiba-tiba menghilang ini berada di kawasan Perhutani RPH Bantur tepatnya di Desa Wojo mempunyai potensi yang sangat besar yaitu potensi pasir besinya. Akan tetapi, potensi ini justru menjadi bumerang bagi pengelola tambang dan membawa dampak positif maupun negatif bagi masyarakat sekitar tambang.

Silang sengkarut skala aktor di tanah Perhutani terbagi menjadi dua yaitu skala lokal dan regional. Pada skala lokal, Perhutani dipandang masyarakat dan pemerintah daerah telah memberi manfaat terbukanya lapangan pekerjaan sekaligus membawa dampak ekologis. Pada skala regional masyarakat melihat bahwa pihak KTIIIIjustru membohongi mereka dengan alasan kegiatan konservasi, yang senyatanya justru meminta tanda tangan dokumen izin UKL UPL. Penjelasan skala keterlibatan aktor dalam hadirnya KTI III disajikan pada tabel 3 .

Tabel 3

Skala Keterlibatan Aktor di Tanah Perhutani

\begin{tabular}{|c|c|c|c|c|}
\hline Skala & Aktor & Kontribusi & Dampak & Resolusi \\
\hline Lokal & Perhutani & $\begin{array}{l}\text { Bertambahnya pendapatan desa } \\
\text { walaupun tidak terlibat langsung } \\
\text { dalam kegiatan penambangan, } \\
\text { juga mendapatkan bagian seperti } \\
\text { sumbangan dana, sembako, dan } \\
\text { terserapnya tenaga kerja di Desa } \\
\text { Wojo. }\end{array}$ & $\begin{array}{l}\text { Masyarakat terbelah menjadi } \\
\text { dua kubu yaitu pro dan } \\
\text { kontra. Kelompok pro seperti } \\
\text { pemerintah desa, masyarakat } \\
\text { yang bekerja sebagai } \\
\text { penambang dan yang diberi } \\
\text { sembako. } \\
\text { Sedangkan kelompok kontra } \\
\text { seperti masyarakat yang lahan } \\
\text { pertaniannya diambil untuk } \\
\text { wilayah pengerukkan pasir besi } \\
\text { dan yang aksesibilitas jalannya } \\
\text { rusak karena dilewati oleh truk } \\
\text { pengangkut hasil tambang. }\end{array}$ & $\begin{array}{l}\text { Perbaikan } \\
\text { jalan desa dan } \\
\text { pemberian } \\
\text { bantuan sembako. }\end{array}$ \\
\hline
\end{tabular}


Lanjutan Tabel 3.

\begin{tabular}{|c|c|c|c|c|}
\hline Skala & Aktor & Kontribusi & Dampak & Resolusi \\
\hline \multirow[t]{3}{*}{ Regional } & $\begin{array}{l}\text { Pemerintah } \\
\text { Daerah }\end{array}$ & $\begin{array}{l}\text { Besaran pendapatan } \\
\text { pertambangan yang masuk ke } \\
\text { pemerintah daerah belum bisa } \\
\text { terlihat dengan pasti karena } \\
\text { KTI merupakan pertambangan } \\
\text { rakyat. }\end{array}$ & $\begin{array}{l}\text { Pemerintah daerah tidak } \\
\text { mendapatkan keuntungan dari } \\
\text { hadirnya KTI III. }\end{array}$ & - \\
\hline & & $\begin{array}{l}\text { Perangkat desa berelasi } \\
\text { dengan Perhutani, KTI III, dan } \\
\text { Pemerintah Kabupaten Malang. } \\
\text { Perangkat desa juga diajak } \\
\text { rembug dengan aktor-aktor } \\
\text { yang berkepentingan sehingga } \\
\text { mereka mengerti benar dengan } \\
\text { permasalahan yang terjadi di } \\
\text { Pantai Golo. }\end{array}$ & $\begin{array}{l}\text { Masyarakat terbelah menjadi } \\
\text { dua kelompok, yang mana } \\
\text { mereka dibenturkan oleh } \\
\text { kompetitor KTI III dengan } \\
\text { alasan reboisasi hutan. } \\
\text { Akibatnya masyarakat } \\
\text { bingung untuk meminta } \\
\text { pertanggungjawaban apakah } \\
\text { dari pihak KTI III ataukah } \\
\text { pemerintah desa. }\end{array}$ & - \\
\hline & & $\begin{array}{l}\text { Masyarakat di Desa Wojo } \\
\text { awalnya menyambut baik adanya } \\
\text { KTI III karena pihak internal } \\
\text { mengemukakan kehadiran } \\
\text { mereka untuk melakukan } \\
\text { kegiatan konservasi, sehingga } \\
\text { mereka berbondong-bondong } \\
\text { menghadiri penanaman pohon } \\
\text { yang dilakukan oleh KTI III. }\end{array}$ & $\begin{array}{l}\text { Masyarakat merasa dibohongi } \\
\text { karena saat mereka mendatangi } \\
\text { kegiatan yang semula } \\
\text { melakukan konservasi menjadi } \\
\text { kegiatan dimana KTI III } \\
\text { meminta tanda tangan atas } \\
\text { dokumen-dokumen yang } \\
\text { digunakan sebagai perizinan } \\
\text { pertambangan yakni UKL UPL. }\end{array}$ & - \\
\hline
\end{tabular}

Permasalahan mulai mucul ketika ada penyerapan tenaga kerja yang tidak merata sehingga menimbulkan kecemburuan sosial. Adapun warga setempat yang terlibat dengan KTI III bekerja sebagai penggarap sisa-sisa bekas galian pasir yang kemudian dibentuk menjadi taman-taman. Selain itu juga terdapat warga yang bekerja sebagai penjaga keamanan. Menurut informan $\mathrm{Kr}$ selaku salah satu perangkat Desa Wojo, terdapat sekitar 500 warga yang dipekerjakan di KTI III. Aktivitas penambangan pasir besi mampu menghasilkan 50 dumtruck perhari, dengan dua kali balik pulang pergi. Satu unit dumtruck berisi 12 ton pasir besi ditambah dengan beban truk 4 ton, sehingga total beban keseluruhan 16 ton. Hal ini memberikan dampak kerusakan jalan akibat beban muatan dumptruck. Kerusakan terparah justru terjadi di luar Desa Wojo yakni Desa Sumberbening yang merupakan akses pintu keluar dari jalur lintas selatan menuju tempat penampungan pasir di wilayah Sengguruh.

Kondisi ini menjadi stimulus bagi warga sekitar untuk memblokir jalan dan menuntut KTI III untuk segera memperbaiki jalan. Hal ini juga dilakukan melalui protes dan demo ke lokasi tambang. Sehingga dapat dipastikan bahwa sejak awal tambang beroperasi sudah banyak mendapatkan protes keras dan penolakan dari masyarakat sekitar. Protes keras juga dilakukan oleh sebagian masyarakat Wojo yang sangat kontra sekali terhadap keberadaan tambang. Akan tetapi, disinyalir bahwa masyarakat yang kontra ini ternyata didasari atas kecemburuan sosial karena tidak mendapatkan bagian.

\section{Pasir Besi dan Lingkar Kuasa Perhutani}

Relasi kuasa antara Perhutani dengan pemerintah Desa Wojo hanya sebatas administrasi serta perizinan persoalan tebang-menebang, izin penggunaan lahan tepi hutan (tetelan), serta izin penanaman komoditas tani. Relasi antara Perhutani dengan masyarakat Desa Wojo selain untuk urusan administrasi yang telah disebutkan, juga untuk urusan sosial kemasyarakatan yang ditandai dengan keberadaan polisi hutan (polhut).

Pada urusan pengelolaan berskala besar, relasi kuasa yang dibangun dengan KTI III bersifat ekonomis dan politik. Letak hubungan ekonomi terlihat pada hitungan 
kapasitas hasil pengelolaannya, jangka waktu pengelolaan, serta Dana Bagi Hasil (DBH). Secara politis, Perhutani masih di bawah kepentingan pihak-pihak elite politik yang ada di DPRD ataupun pemerintah daerah. Misalkan terkait RTRW otomatis Perhutani akan terkait dengan kerja Bappeda Kabupaten Malang serta Badan Lingkungan Hidup. Secara langsung pula, Perhutani memiliki kawasan Kesatuan Pengelolaan Hutan (KPH) yang berada dalam garis koridor Kerangka Rencana Pembangunan Daerah Malang selama lima tahun kedepan. Sehingga saat ada aktivitas industri pertambangan maupun lainnya, Perhutani tetap mengikuti aturan keputusan daerah.

Terkait dengan pengawasan area wilayah RPH yang melibatkan Pantai Golo, maka peran Perhutani adalah tetap menegakkan hukum dan aturan yang berlaku seperti UU Nomor 27 Tahun 2007 tentang Masyarakat Pesisir, PP Nomor 32 Tahun 1990 tentang Hutan Lindung serta peraturan skala daerah. Misalnya saat adanya penolakan terhadap PT Marmora, pihak Perhutani muncul sebagai pihak pengawas hutan lindung dan memutuskan untuk menolaknya. Peran Perhutani tidak selalu menyesuaikan dengan aturan ataupun hukum yang berlaku, tetapi juga dipengaruhi oleh hubungan politik dengan Organisasi Pemerintah Daerah (OPD) lainnya. Kekuatan ekonomi dari pihak swasta yang akan masuk juga harus menjadi bahan pertimbangan. Maka dari itu, hasil temuan di lapangan terjelaskan bahwa jejaring relasi kekuasaan lokal justru yang terbangun atas hadirnya KTI III. Pihak Perhutani mempolitisasi masyarakat dan Pemerintah Desa Wojo, tetapi dalam relasi kuasa secara regional justru Perhutani dipolitisasi oleh KTI III dan pemerintah Kabupaten Malang.

\section{SIMPULAN}

Perhutani melakukan politisasi sumber daya, tetapi di lain sisi juga terpolitisasi oleh aktor-aktor lain seperti pihak KTI III dan pemerintah daerah. Pada ketiga dimensi yaitu harian, episodik, dan sistemik ditemukan dua konfigurasi dari peran Perhutani yaitu mempolitisasi kawasan Pantai Golo dengan melakukan perubahan Resort Polisi Hutan (RPH) dan dipolitisasi oleh pemerintah serta KTI III melalui perubahan Rencana Tata Ruang Wilayah/ RT-RW. Dalam kedua skala lokal dan regional, Perhutani dipandang masyarakat dan pemerintah daerah telah memberi manfaat berupa terbukanya lapangan pekerjaan sekaligus membawa dampak kerusakan ekologis. Secara jejaring relasi kekuasaan lokal, Perhutani mempolitisasi masyarakat dan pemerintah Desa Wojo, tetapi dalam relasi kekuasaan regional Perhutani justru dipolitasi oleh KTI III dan pemerintah Kabupaten Malang.

Posisi keterlibatan Perhutani secara detail masih harus ditelusuri lebih dalam lagi pada proses selanjutnya karena data yang diperoleh sampai pada tahap ini hanya berasal dari pihak-pihak lain yang sama-sama terlibat tetapi tidak mengatahui secara rinci bagaimana prosedur yang dilaksanakan oleh Perhutani dalam kaitannya dengan pertambangan KTI III di Pantai Golo, Desa Wojo.

Saran yang perlu diperhatikan secara teknis antara lain tahapan penelitian selanjutnya diharapkan dapat menelusuri data ke Perhutani dengan menggunakan tema lain seperti berbicara mengenai wisata dan pengembangan potensi sumber daya alam di pesisir pantai sebelah selatan Kabupaten Malang. Saran substansial yang diperlukan adalah dibutuhkannya keterbukaan informasi dan data dari Perhutani demi keberlanjutan ruang ekologi dan ekonomi masyarakat di Desa Wojo, Kecamatan Gedangan, Kabupaten Malang.

\section{DAFTAR PUSTAKA}

Peraturan Daerah Kabupaten Malang no. 3 Tahun 2010 tentang Rencana Tata Ruang Wilayah Kabupaten Malang. 2010.

Peraturan Pemerintah no. 72 Tahun 2010 tentang Perusahaan Umum (Perum) Kehutanan Negara 2010.

Amiruddin, L., Nurhadi, I., \& Rozalinna, G. 2016. Struktur Sosial Masyarakat Lingkar Luar Tambang Pasir Besi: Laporan akhir hibah penelitian Fakultas Ilmu Sosial dan Ilmu Politik. Malang: 
Fakultas Ilmu Sosial dan Ilmu Politik, Universitas Brawijaya.

Bryant, \& Bailey. 2005. Third World Political Ecology. London \& New York: Routledge.

Denzin, \& Lincoln. 2009. Handbook of Qualitative Research. Yogyakarta: Pustaka Pelajar.

McMichael, H. 2009. The lapindo Mudflow Disaster: Environmental, Infrastructure and Economic impact. Bulletin of Indonesian Economic Studies, 45(1), 73-83.

Noor, R., \& Ni'am, L. 2011. Penataan Ruang dan Pengelolaan Sumber Daya. Wacana Jurnal Ilmu Sosial Transformatif, Penataan Ruang dan Pengelolaan Sumberdaya. Edisi 26 Tahun XIII 2011.

Nurhadi, I., \& Rozalinna, L. A. 2015. Struktur Sosial Baru Pasca Kehadiran Perusahaan
Tambang (Analisis Strukturasi Pierre Bourdieu Pada Masyarakat Desa Wojo, Kecamatan Gedangan, Kabupaten Malang): Laporan akhir hibah penelitian Fakultas Ilmu Sosial dan Ilmu Politik. Malang: Fakultas Ilmu Sosial dan Ilmu Politik, Universitas Brawijaya.

(t.thn.). Rencana Induk Penelitian (RIP) Universitas Brawijaya tentang Sasaran Tahap Kedua Tahun 2106-2020 untuk Menuju Daya Saing Regional Asia dan Kawasan Tropik. Malang: Lembaga Penelitian dan Pengabdian Kepada Masyarakat, Universitas Brawijaya.

Tim Riset Java Collapse. 2010. Lapindo, Jer Basuki(ku) Mawa Bea(mu). Dalam Java Collapse, dari Kerja Paksa Hingga Lumpur Lapindo. Sleman: Insist dan Walhi.

Yin, R. K. (2013). Studi Kasus Desain E Metode. Jakarta: Raja Grafindo Persada. 